\title{
Identification of novel targets of diabetic nephropathy and PEDF peptide treatment using RNA-seq
}

Ana Rubin ${ }^{1 \dagger}$, Anna C. Salzberg ${ }^{2 \dagger}$, Yuka Imamura ${ }^{2}$, Anzor Grivitishvilli and Joyce Tombran-Tink ${ }^{1,3^{*}}$

\begin{abstract}
Background: Diabetic nephropathy (DN) is a major complication of type1 and type 2 diabetes. Understanding how diabetes regulate transcriptome dynamics in DN is important for understanding the biology of the disease and for guiding development of new treatments.
\end{abstract}

Results: We analyzed the kidney transcriptome of a DN mouse model, D2.B6-Ins2 ${ }^{\text {Akita }}$ /MatbJ, before/after treatment with P78-PEDF. Age, weight, and gender-matched mice and wild-type (wt) littermates were treated at 6 weeks (early treatment) or 12 weeks (late treatment) of age for the duration of 6 weeks. Animals were implanted with an osmotic mini pump delivering $0.3 \mathrm{ug} / \mathrm{g} /$ day P78-PEDF or vehicle. Using RNA-seq, we identified14,316 transcripts (12,328 coding;1,988 non-coding) that were significant and reliably expressed (FPKM > $=1)$ in diabetic kidneys. Expression of 1,129 (7.9\%) including 901 coding genes was altered by diabetes with log2 fold changes (FC) between -86.2 and +86.0 ( $q$ < 0.05) compared to wt. Of these, $164(14.5 \%)$ showed increased and 965 (85.5\%) decreased expression with FC > 1.5. Coding genes with highest FC in diabetic kidneys include Nhej1 (32.04), Ept1 (8.6), Srd5a2 (-6.55), Aif1 (-6.05), and Angptl7 (-4.71).

Early and late stage diabetic groups receiving continuous infusion of P78 showed altered expression of 316/14,316 (2.2\%) transcripts, including 121 coding genes compared to non-treated diabetic controls. Of these, 183 were upregulated and 133 downregulated with FC +50.9--93.3 ( $q<0.05)$. P78 reversed diabetes-induced changes in 138/1129 (12.2\%) transcripts, including 49/901 (5.44\%) coding genes. Nhej1 (-37.94), Tceanc2 (5.76), Ept1 (-4.45), Ugt1a2 (3.03), and Tmsb15I (-3.0) showed the highest FC with treatment. The DNA repair gene, Nhej1 with the greatest FC in diabetic kidneys was completely restored to control levels by both early and late P78 treatments. Expression of other coding genes regulated by diabetes with FC > =(+/-) 1.5 and completely reversed by P78 include Mamdc4, Kdm4b, Tmem252, Selm, and Hpd. RT and QRT-PCR validated expression of gene with FC > (+/-)2.0. Transcriptome changes were also observed between early and late-stage treatments.

Precursor non-coding miRNAs showed the highest fold changes in expression in the diabetic and P78 treatment groups. Several diabetic-induced changes were reversed in direction of expression by treatment including Gm24083, GM25953, miR1905, Gm25535, Gm27903, and miR196a1 with FC > =(+/-)20.

From Ingenuity pathway analysis (IPA), mitochondrial dysfunction, Nrf-2- mediated oxidative stress and renal injury pathways emerged as key mechanisms in DN. DN-enriching genes in these pathways were reduced in number or regulated in the opposite direction by treatment.

(Continued on next page)

\footnotetext{
* Correspondence: jxt57@psu.edu; jttink@aol.com

${ }^{\dagger}$ Equal contributors

'Department of Neural and Behavioral Sciences, Penn State College of

Medicine, Hershey, USA

${ }^{3}$ Department of Ophthalmology, Penn State College of Medicine, Hershey,

PA 17033, USA

Full list of author information is available at the end of the article
} 
(Continued from previous page)

Conclusions: Unique biomarkers and canonical pathways identified in this study may hold the key to understanding mechanisms of DN pathobiology with value for clinical translation. Our data suggest that mitochondrial dysfunction, genotoxicity and oxidative stress are principal events in DN and that P78-PEDF holds promise for its management.

Keywords: Diabetic nephropathy, PEDF P78 peptide, Global transcriptome changes, RNAseq, Canonical pathways, miRNA, Nhej1, Ept1, Mamdc4, Kdm4b

\section{Background}

The prevalence of diabetes in the world has been estimated at $2.8 \%$ in 2000 , and is projected to increase to $4.4 \%$ by 2030 [1]. The disease currently affects approximately $8.3 \%$ of the US population, and is a leading cause of morbidity and mortality. Diabetes is a major cause of stroke, blindness, heart disease, and end-stage renal disease (ESRD) [2]. Among these sequelae, diabetic nephropathy (DN) is one of the most common complications of both Type 1 and Type 2 diabetes [3].

The pathophysiology of DN is complex and multiple mechanisms contribute to its development and outcome. Early hemodynamic changes and defective autoregulation of glomerular filtration rate lead to glomerular hyperfiltration and hyperperfusion [4]. Mechanisms involving glycosylation of tissue proteins [5], activation of Protein kinase $\mathrm{C}$ [6], and the Aldose reductase pathway [7] are believed to promote tissue damage, glomerular basement membrane thickening, glomerular hypertrophy and mesangial expansion. Other factors linked to the development and progression of DN include the expression of nephrin [8], inflammatory cytokines, vascular endothelial growth factor (VEGF) [9], lipid mediators [10], and reactive oxygen species [11]. Although, there is evidence that genetic predisposition influences the incidence and severity of $\mathrm{DN}$, the low likelihood of identifying a single gene for the pathogenesis of DN has shifted research towards a multigene approach to understand mechanisms and etiology of the disease [4].

Current management of DN centers on preventing the development of risk factors such as hypertension, hyperglycemia, and dyslipidemia, early diagnosis, and antihypertensive therapy to reduce rate of decline in renal function [12]. Despite advancements in therapy, DN continues to be the most common cause of ESRD and requires dialysis in the U.S. [3]. The human and economic costs associated with ESRD raise the importance of risk factor reduction and the need to identify novel therapeutic targets to manage diabetes-induced kidney damage.

A large number of studies have now documented the protective role of pigment epithelium-derived factor (PEDF) against a wide range of oxidative and excitotoxic insults [13-15]. The neuroprotective, anti-angiogenic and antiinflammatory properties of PEDF have been exploited in many preclinical therapeutic strategies [13] especially since the gene is expressed in several tissues [16] including the kidney where the highest expression is in the glomeruli [17]. In diabetes, serum levels of PEDF increase whereas tissue levels in the eye and kidney decrease in diabetic retinopathy and diabetic nephropathy respectively [18-20]. Such studies imply that restoring PEDF levels could reduce damage to tissues in diabetes. For example, increasing PEDF levels in the kidney by injecting an adenovirus expressing the protein significantly alleviates microalbuminuria in the early stages of diabetes [21].

Because PEDF is a large $50 \mathrm{kD}$ protein it has limited usefulness as a therapeutic agent in many cases. However, an active 44 amino acid fragment of PEDF (P78-PEDF) can block ischemic damage to retinal ganglion cells and reduce neuronal death, vascular abnormalities and inflammatory changes in a mouse model of diabetic retinopathy [22, 23]. We have shown that continuous infusion of this peptide in diabetic mice protects against development of diabetic nephropathy as indicated by reduced albuminuria, blood urea nitrogen, macrophage recruitment and expression of inflammatory cytokines and fibrotic markers, balanced nephrin expression, and decreased histological changes in diabetic kidneys [24]. In a proof of concept extension of those studies we confirmed that continuous systemic infusion of P78 blocks the progression of well-established diabetic nephropathy in the Ins2 $2^{\text {Akita }}$ mouse model of DN [25]. Here we used kidney samples obtained from the recently published proof of concept experiments [25] to study transcriptome changes in these non-treated and P78-treated diabetic nephropathy mice to identify novel gene candidates and pathways as regulators in the pathogenesis of $\mathrm{DN}$.

\section{Methods}

P78 drug delivery in diabetic Ins $2^{A k i t a}$ mice

Kidney tissue samples were obtained from a recently published study that tested physiological effects of P78 on kidney function and pathology [25]. Animals were treated as previously described [25] prior to extracting RNA for RNA-seq analysis. The animal studies were approved by the Penn State University College of Medicine Institutional Animal Care and Use Committee, and performed in strict accordance with the recommendations in the Guide for the Care and Use of Laboratory Animals of 
the National Institutes of Health. All experiments were conducted using male D2.B6-Ins $2^{\text {Akita }} /$ MatbJ diabetic animals and their wild type (WT) littermate mice (DBA/2 J background), recommended by the Animal Models of Diabetes Complications Consortium (AMDCC) as a model of DN [26, 27]. The diabetic D2.B6-Ins $2^{A k i t a}$ mice develop hyperglycemia at 3 weeks of age and all treatment carried out when the mice were either 6 weeks ( 3 weeks hyperglycemic exposure; early stage treatment) or 12 weeks (9 weeks hyperglycemic exposure; late stage treatment) of age. Only mice with blood glucose levels $>350 \mathrm{mg} / \mathrm{dl}$ (measured using Accu-Chek glucometer, Boehringer Mannheim, Indianapolis, IN) were considered diabetic and used in the study.

The drug tested was P78, a small PEDF active peptide $[22,23]$, generated by methods previously described $[25,28]$. Briefly, P78 peptide at a dose of $0.3 \mu \mathrm{g} / \mathrm{g} /$ day or vehicle (phosphate-buffered saline; PBS) was administered by continuous subcutaneous infusion via the osmotic minipump (no. 2006; Alzet, Durect, Palo Alto, CA), implanted dorsally between the shoulders of the animals as previously described [25, 29-31]. Transcriptome analysis of wild-type and diabetic kidney samples were performed at two stages of diabetes where treatment was initiated at an early stage ( 6 weeks of age; 3 weeks hyperglycemic) and late stage (12 weeks of age; 9 weeks hyperglycemic). Age, gender, and weight matched diabetic Ins2Akita and wild-type non-diabetic controls were used in the study. All animals including wild-type were implanted with an osmotic minipump infused with either vehicle (wt and diabetic controls) or the P78 peptide (diabetic mice). Duration of treatment was 6 weeks with either peptide or vehicle. One group received treatment at the early stage of diabetes (ET, early treatment) at 6 weeks of age and the experiment terminated at 12 weeks of age. Treatment in the second group was initiated at late stage diabetes (LT, late treatment) at 12 weeks of age and terminated at 18 weeks of age. Mice were provided ad lib access to food and water and were euthanized at the end of the experimental period. Kidney samples for RNA extraction were immediately harvested and frozen in liquid nitrogen at the termination of the experiment.

\section{Tissue samples preparation and RNA isolation}

For RNAseq we used 13 kidney tissue samples from wild-type mice, 7 from the diabetic Ins $2^{\text {Akita }}$ mice, 8 from early P78 treatment of diabetic Ins $2^{\text {Akita }}$ mice, and 7 from late P78 treatment the diabetic Ins2 ${ }^{\text {Akita }}$ mice [25]. Total RNA was extracted using mirVana kit (Life Technologies) with some modifications. Briefly, a bead mill homogenizer (Bullet Blender, Next Advance) was used to homogenize the tissue using a safe-lock microcentrifuge tube (Eppendorf) and a mass of stainless steel beads (Next Advance, cat\# SSB14B) equal to the mass of the tissue. Immediately after two volumes of lysis buffer were added to the tube, samples were mixed in the Bullet Blender for $1 \mathrm{~min}$ at a speed of six. Samples were visually inspected to confirm desired homogenization and then incubated at $37^{\circ} \mathrm{C}$ for $5 \mathrm{~min}$. The lysis buffer was added up to $0.6 \mathrm{ml}$, and samples were mixed in the Bullet Blender for $1 \mathrm{~min}$. Optical density values of extracted RNA were measured using NanoDrop (Thermo Scientific) to confirm an $\mathrm{A}_{260}: \mathrm{A}_{280}$ ratio above 1.9. RNA integration number (RIN) was measured using BioAnalyzer (Agilent) RNA 6000 Nano Kit to confirm RIN above 7.

\section{Library preparation and sequencing}

The cDNA libraries were prepared using SureSelect Strand Specific RNA Library Preparation Kit (Agilent) as per the manufacturer's instructions. Briefly, polyA RNA was purified from $1000 \mathrm{ng}$ of total RNA using oligo (dT) beads. Extracted RNA was subjected to fragmentation, reverse transcription, end repair, 3'-end adenylation, adaptor ligation and subsequent PCR amplification and SPRI bead purification (Beckman Coulter). The unique barcode sequences were incorporated in the adaptors for multiplexed high-throughput sequencing. The final product was assessed for its size distribution and concentration using BioAnalyzer High Sensitivity DNA Kit (Agilent) and Kapa Library Quantification Kit (Kapa Biosystems). 12 libraries were pooled and diluted to $2 \mathrm{nM}$ in EB buffer (Qiagen) and then denatured using the Illumina protocol. The denatured libraries were diluted to $10 \mathrm{pM}$ by prechilled hybridization buffer and loaded onto TruSeq SR v3 flow cells on an Illumina HiSeq 2500 and run for 50 cycles using a single-read recipe (TruSeq SBS Kit v3) according to the manufacturer's instructions (Illumina).

\section{Quality control, mapping and quantification of RNA-Seq reads}

Illumina CASAVA pipeline Version 1.8 was used to extract de-multiplexed sequencing reads. FastQC (version 0.11.2) (http://www.bioinformatics.babraham.ac.uk/projects/fastqc/) was used to validate the quality of the raw sequence data. Additional quality filtering used FASTX-Toolkit (http:// hannonlab.cshl.edu/fastx_toolkit) using a quality score cutoff of 20. Next, alignment of the filtered reads to the mouse reference genome ( $\mathrm{mm} 10)$ was done using Tophat (version 2.0.9) [32] allowing 2 mismatches. Picard (version1.102) (https://github.com/broadinstitute/picard) was used to assess proportion of mapped bases to coding, UTR, intronic, and intergenic regions, respectively. Picard was used to find coverage across gene body to determine 5'- or 3'- bias. FPKM (Fragments Per Kilobase of Exon Per Million Fragments Mapped) values were calculated using Cufflinks Version 2.0.2 [33] as provided with the Ensembl gene annotation (release 78 ). 


\section{Differential Gene Expression (DEG) analysis}

Only reliably expressed genes were included in the analysis, defined to be those with at least 2 samples with FPKM $>=1$. The ComBat function of the sva v3.10.0 R package was used for batch normalization of the FPKM values. The DEGexp function of the DEGseq v1.18.0 $\mathrm{R}$ package [34] was used to identify differentially expressed genes (DEG) between diabetes and control (DvC), treatment and diabetes (TvD), early treatment and diabetes $(\mathrm{ETVD})$ and late treatment and diabetes (LTvD), using the Likelihood Ratio Test method. Significantly DEG were defined to be those with q-value $<0.05$ calculated by the Storey et al. 2003 method.

\section{Visualization}

The batch adjusted RNA-seq FPKM values of the reliably expressed genes were averaged for samples in each category: C, D, ET and LT. A heatmap of the Z scaled resulting FPKM values was generated using the heatmap.2 function of the gplots $\mathrm{R}$ package, with parameters "average" for clustering method and 1-correlation for distance. The $\mathrm{Z}$ scaling was performed with the genefilter v1.46.1 R package. A volcano plot was generated of the $-\log 10(p$-value) vs. $\log 2$ (normalized FC) of the $\mathrm{DvC}$ and TvD DEG analyses, with points with $\mathrm{q}<0.05$ and $\operatorname{abs}(\log 2($ normalized FC $))>=1$ (i.e. a FC threshold of 2 ) colored red for $\mathrm{DvC}$ and green for TvD. Labeled genes have a q-value $<0.05$ and abs $(\log 2($ normalized FC $))>=2$ (i.e. a FC threshold of 4). Quad Venn diagrams showing the number of significant DEG genes and protein coding subsets for various comparisons were generated using the VennDiagram v1.6.9 R package.

\section{Functional analysis}

The Tox Analysis function of Ingenuity Pathway Analysis (IPA) (QIAGEN, California) was used to create gene sets based on biological processes and toxicological responses to xenobiotic insult using the mammal filter (human, rat, mouse) and the following tissues in turn: adipose, brain, heart, kidney, liver, retina and all tissues. IPA Build 201503-23.

\section{Statistical analysis}

Statistical tools embedded in the previous instruments and statistical packages were applied. Significant DEG were defined to be those with q-value $<0.05$ calculated by the Storey et al. 2003 method.

\section{RT-PCR}

Total mRNA from treated, non-treated, and wt kidney samples was extracted for PCR using the RNAeasy Mini Kit (Qiagen) First-strand cDNA of isolated mRNA was synthesized using Superscript First Strand cDNA Synthesis reagents (Invitrogen). Gene-specific primers were designed using NCBI Primer-Blast primer design tool (Primer3web version 4.0.0) and primer information listed in the table below. Reverse transcription (RT)-PCR was carried out using 80 ng cDNA from pooled samples, PCR master mix reagents (Invitrogen), annealing temperature of $58{ }^{\circ} \mathrm{C}$, and 35 amplification cycles. PCR products were resolved by $1 \%$ agarose gel electrophoresis. Quantitative RT-PCR (qrt-PCR) was also performed using 20 ng cDNA and these primers to cross-validate, quantitate, and confirm gene expression changes and trends. For qrt-PCR, a two-step amplifying protocol was used with iQ SYBR Green Supermix solution (Bio-Rad). $C_{t}$ (threshold cycle) was used to determine gene expression levels.

\section{Results}

Global transcriptome changes

Results obtained from DEGseq analysis applied on RNAseq FPKM (Fragments per kilobase of exon per million

\begin{tabular}{|c|c|c|c|}
\hline Genes & ENSEMBL \# & Primer sequence $\left(5^{\prime}-3^{\prime}\right)$ & Amplicon size (bp) \\
\hline Nhej1 & ENSMUSG00000026162 & $\begin{array}{l}\text { F: } 5^{\prime} \text { CCAAGCACGGTTATGCCTTG 3' } \\
\text { R: 5' CAGGCTCACACCCATCAGAG 3' }\end{array}$ & 344 \\
\hline Ept1 & ENSMUSG00000075703 & $\begin{array}{l}\text { F: } 5^{\prime} \text { TTCAGCCAGAGATGCCAGTG } 3^{\prime} \\
\text { R: } 5^{\prime} \text { CAGGCACCCAATCCTAGCAA } 3^{\prime}\end{array}$ & 274 \\
\hline Cyp4a14 & ENSMUSG00000028715 & $\begin{array}{l}\text { F: 5' TTGCCAGAATGGAGGATAGGAA 3' } \\
\text { R: 5' TGGAGCGTCCATCTGGGAAG 3' }\end{array}$ & 324 \\
\hline Ugt1a2 & ENSMUSG00000090171 & $\begin{array}{l}\text { F: 5' GCCCCTTCGAGGAATCTCAG 3' } \\
\text { R: 5'AGGTCTTCTCAATGTCGCTCAG 3' }\end{array}$ & 278 \\
\hline KDM4B & ENSMUSG00000024201 & $\begin{array}{l}\text { F: 5' TCCACCAACACCCCTCAATG 3' } \\
\text { R: 5' AAGGGGTTGTTCCCTGTGAG 3" }\end{array}$ & 218 \\
\hline Selm & ENSMUSG00000075702 & $\begin{array}{l}\text { F: 5' CACCAACTACCGACCGGATT 3' } \\
\text { R: 5' TCCTGTACCAGCGCATTGAT 3' }\end{array}$ & 261 \\
\hline Mamdc4 & ENSMUSG00000026941 & $\begin{array}{l}\text { F: 5' GCTCCTGGGCACTTCCTATC 3' } \\
\text { R: 5' GAGTCACATTGTCCACCCCA 3' }\end{array}$ & 334 \\
\hline
\end{tabular}


fragments mapped) showed significant differences in coding and non-coding genes expressed in the kidney among control (C, wild-type), diabetic (D), early (ET), and late (LT) P78 treatment in the Ins2Akita mouse model of diabetic nephropathy $(\mathrm{DN})$. Below we provide results for protein coding and non-coding genes that were regulated in the diabetic kidney relative to P78 treated and wt controls: The comparisons are (1) diabetic relative to wild type (DvC), (2) P78 treated relative to non-treated diabetic (TvD), (3) diabetic returned to normal levels by treatment (early and late stage treatment), and (4) P78 early stage treatment (ET) compared to late stage treatment (LT). Early (ET) and late (LT) P78 treatments are grouped in the TvD analyses to determine all gene targets of the treatment whether given at early or late stages of diabetes. These are later separated in the study to determine those targets that were unique to ET and those unique to LT.

\section{Global expression changes}

The heatmap in Fig. 1 and volcano plot in Fig. 2 show global transcriptome changes in control, diabetic, and P78 early and late treatments in kidney tissues of the Ins $2^{\text {Akita }}$ mouse model of diabetic nephropathy. 43,168 RNA transcripts were identified in the kidney. 25,254 had an FPKM value $>0$ and 14,316 were considered reliably expressed, defined to be those with FPKM $>=1$. Of the 14,316 reliably expressed sequences, 12,328 were protein coding genes and 1,988 non-coding RNA transcripts.

The distribution of all genes (protein-coding and noncoding) with respect to significance (y axis) versus fold changes ( $\mathrm{x}$ axis) is shown in the scatter plot in Fig. 2 $(-\log 10(p$-value) vs $\log 2$ (normalized fold change (FC)). Genes of interest are outside the midline where absolute normalized $\mathrm{FC}>=(+/-) 4$ are colored red for $\mathrm{DvC}$ (diabetic versus wt controls) and green for TvD (early and late stage P78-treated diabetic mice versus diabetic controls). A few genes including Nhej1, Ept1, Cyp4a14, and Ugt1a2, which are significantly regulated by diabetes and treatment with an absolute normalized FC $>=(+/-) 4$, are labeled as examples to show their location and relationship to other points in the plot and to the midline. Many protein-coding and non-coding genes showed small
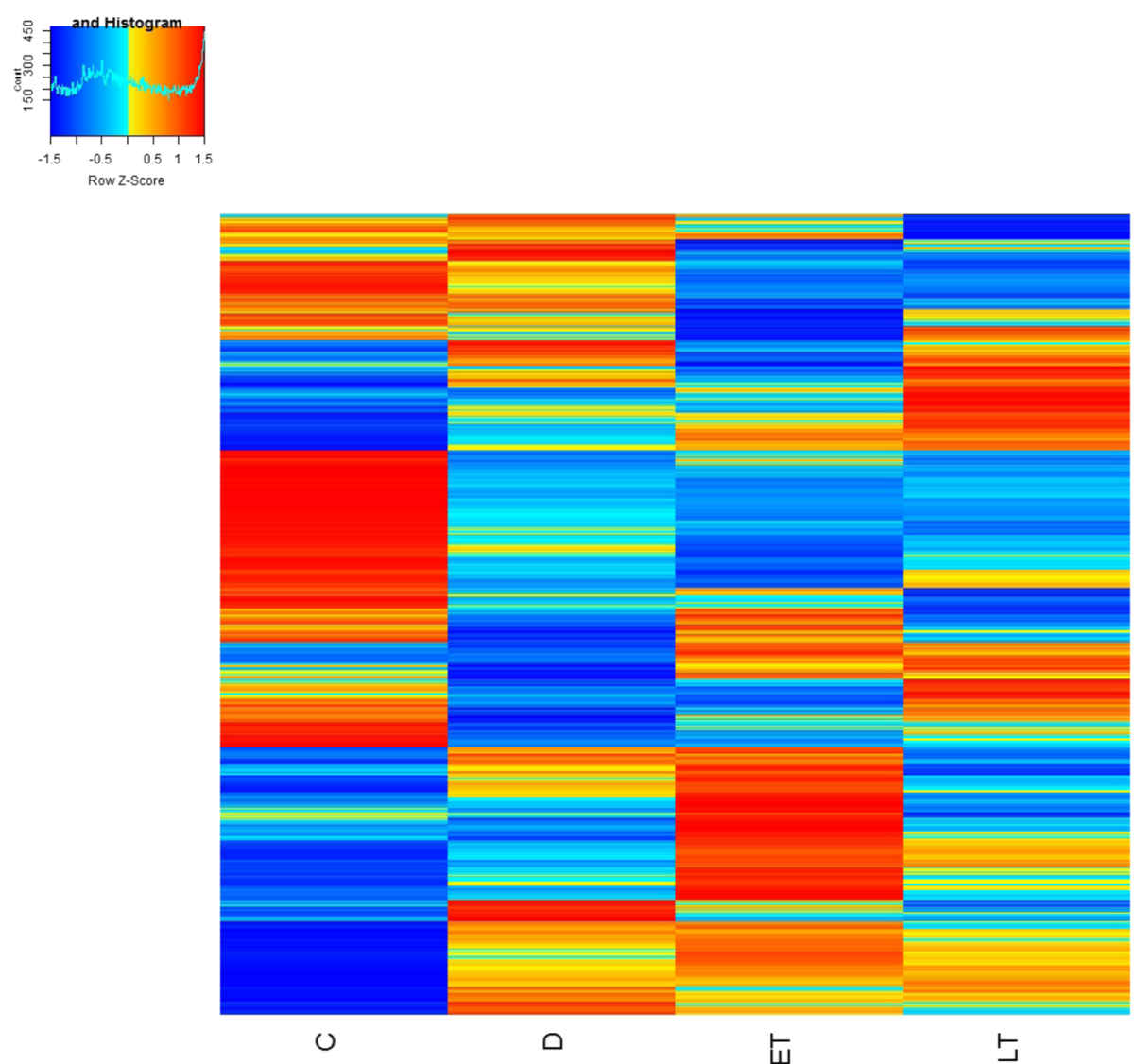

Fig. 1 Heatmap of Z scaled RNA-seq FPKM (Fragments per kilobase of exon per million fragments mapped) values of 14,316 reliably expressed transcripts in kidney samples of the Ins $2^{\text {Akita }}$ mouse model of diabetic nephropathy (DN). FPKM values were averaged for samples in each category (C: control, D: diabetic, ET: early P78 treatment, LT: late P78 treatment) ( $n=7-13)$ 


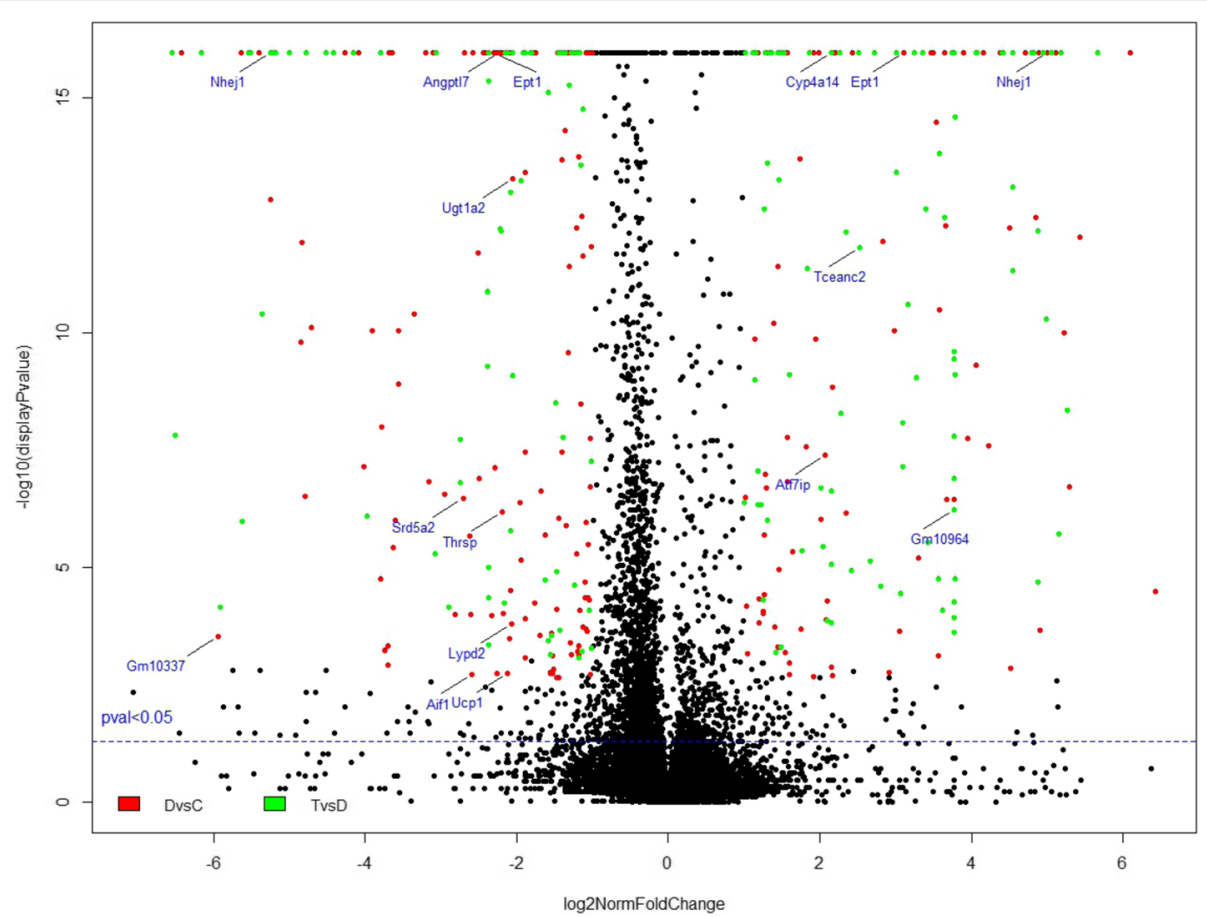

Fig. 2 Volcano Plot showing -log10(p-value) vs log2(normalized fold change (FC)) of RNA-seg FPKM (Fragments per kilobase of exon per million fragments mapped) for all transcripts (protein-coding and non-coding) differentially expressed genes (DEG) in kidney samples of Ins $2^{\text {Akita }}$ mouse model of diabetic nephropathy. Distribution of genes with respect to significance (y axis) versus fold changes ( $x$ axis) is shown. Genes of interest outside the midline where absolute normalized FC $>=+/-4(q<0.05)$ are labeled as examples to show changes in expression levels in diabetic (DvC, Red) or P78 treated diabetic mice (TvD, Green) relative to controls. Horizontal dashed line represents expression value $p=0.05$; above line $p<0.05$; below line: $p>0.05$. Genes outside the midline have $F C>1$

changes in their expression levels in either direction but only those that met our selection criteria of FC $>=(+/-) 1.5$, $\mathrm{q}<0.05$ were of interest in this study and rank-ordered in all tables according to fold changes in either direction.

\section{All transcripts regulated by diabetes and P78}

Gene expression differences in the kidney between the diabetic compared to control $(\mathrm{DvC})$ and P78 treatment compared to diabetic ( $\mathrm{TvD}$, early and late) groups are shown in the Venn diagram in Fig. 3 and in Table 1. These represent all protein-coding and non-coding RNA transcripts that showed statistically significant differential expression (DEG) $(\mathrm{q}<0.05)$. Changes in expression levels were seen in 1237 transcripts in the kidney (a total of all numbers in the Venn diagram). $208(46+51+87+24)$ of these were regulated by both diabetes and treatment. 1,129 RNA transcripts (coding plus non-coding) were regulated by diabetes with $\log 2$ fold changes (FC) ranging between -86.2 and $+86.0(\mathrm{q}<0.05)$ (Table 1). 164 were upregulated and 965 downregulated by diabetes. P78 treatment (early and late; TvD group) altered expression of 316 transcripts with FC between -93.3 and $+50.9(\mathrm{q}<0.05)$. Of these, 183 were upregulated and 133 downregulated. A total of 138/1129 (12.2\%) transcripts whose levels were either increased (51 transcripts) or decreased (87 transcripts) by diabetes were reversed in the direction of their expression to normal levels by P78 treatment (Table 1). While the regulation of most transcripts by diabetes were not reversed by treatment, the effects of P78 in reducing pathology and progression of $\mathrm{DN}$ that we have previously shown $[24,25]$ may be due, in part, to reversing diabetes-induced expression changes in this subset (138) of coding and non-coding RNA transcripts.

\section{Protein-coding genes (mRNA) regulated by diabetes and P78}

Figure 4 and Table 2 show the number of protein coding genes (mRNA) regulated by diabetes and P78. Changes in gene expression occurred in 934 protein-coding genes (all numbers in the Venn diagram) in the kidney of the Ins $2^{\text {Akita }}$ mouse model of $\mathrm{DN}$, with 88 of these $(33+15+$ $34+6)$ regulated by both diabetes and treatment. Diabetes altered expression of 901 genes $(q<0.05)$, of which 71 were upregulated and 830 downregulated by the disease (Table 2 ). P78 (early and late treatment) modulated expression of 121 coding genes with 65 of these showing increased and 56 showing decreased expression levels. P78 treatment 


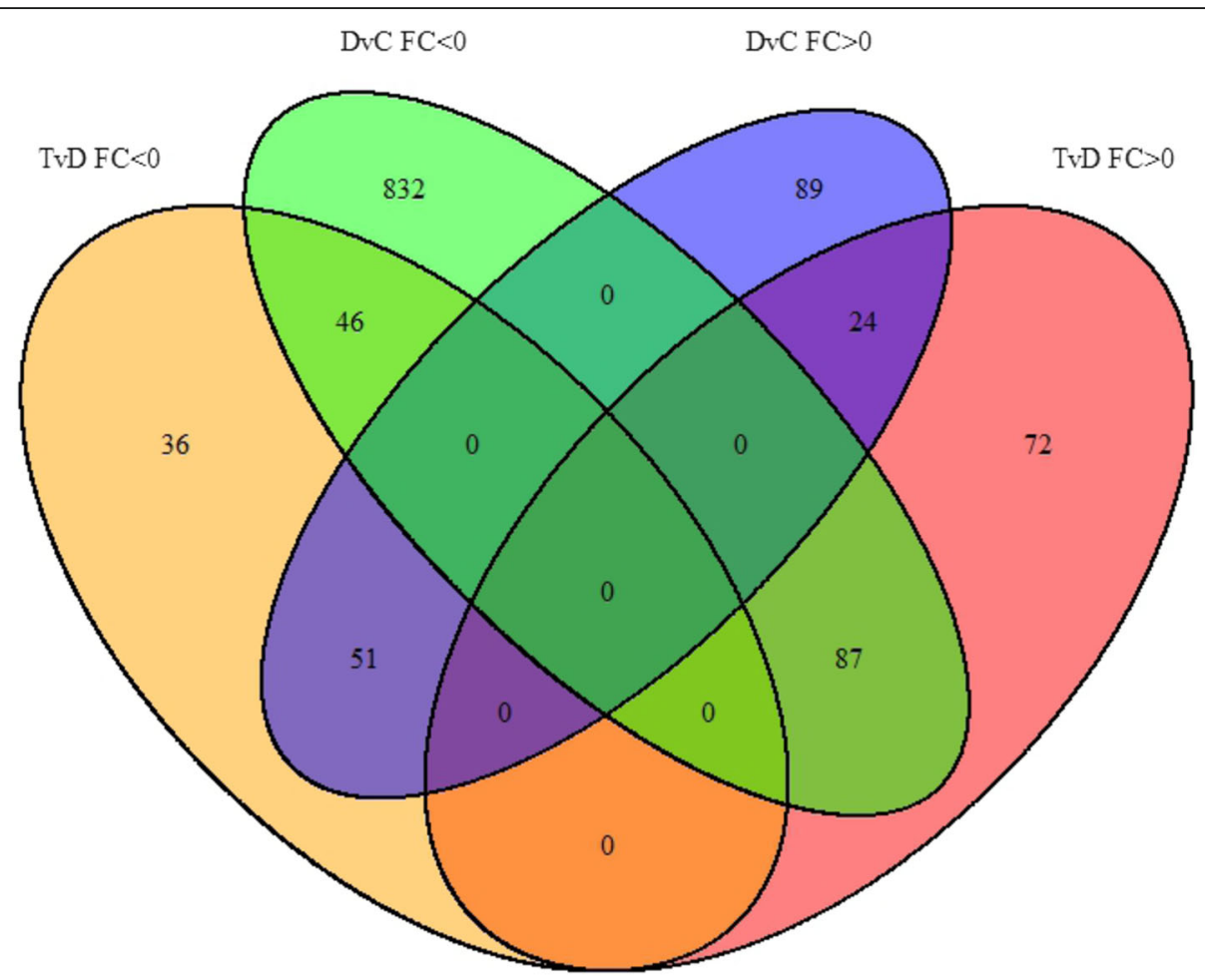

Fig. 3 The Venn Diagram shows RNA-seq data for all RNA biotypes (protein-coding and non-coding) that were regulated by diabetes compared to control (DvC) and by P78 treated compared to non-treated diabetic controls (TvD). FC: fold changes. Blue: DvC - positive FC (FC $>0)$. Green: DvC - negative FC $(F C<0)$. Pink: TvD - positive FC $(F C>0)$. Yellow: TVD - negative FC $(F C<0)$. Changes in expression levels were seen in 1237 transcripts of which 208 were regulated by both diabetes and treatment. 1129 transcripts were regulated in DN, 316 by treatment (early and late), and 138 whose expression levels were altered in DN were reversed by treatment towards control levels $(q<0.05)$

reversed direction of expression of $49 / 901$ (5.44\%) of the protein coding genes regulated in diabetic kidneys towards normal levels (Table 2).

Only protein-coding genes with the highest fold changes induced by diabetes or P78 are shown in Table 3A-C. These represent all differentially expressed genes with absolute $\mathrm{FC}>=(+/-) 1.5(\mathrm{q}<0.05)$ and are rank-ordered by $\mathrm{FC}$ in either direction. Table 3A lists protein-coding genes

Table 1 Number of all transcripts (coding and non-coding) that were significantly regulated in the kidney by diabetes (D), P78 treatment ( $T$, early and late treatment), and those with expression changes in $\mathrm{D}$ that were reversed by $\mathrm{T}$ in the Ins $2^{\text {Akita }}$ mouse model of diabetic nephropathy (DN) $(q<0.05)$

\begin{tabular}{ll}
\hline Group & \# of Genes \\
\hline Upregulated in D & 164 \\
Downregulated in D & 965 \\
Upregulated with T & 183 \\
Downregulated with T & 133 \\
Upregulated in D, reversed by T & 51 \\
Downregulated in D, reversed by T & 87 \\
\hline
\end{tabular}

that were regulated by diabetes of which Nhej1 $(+32.04)$, Ept1 (+8.6), Srd5a2 (-6.55), Aif1 (-6.05), Angptl7 (-4.71), Thrsp (-4.57), Cyp4a14 (+4.4), Ucp1 (-4.35), Atf7ip $(+4.21)$, Lypd2 (-4.2), and Ugt1a2 $(-4.13)$ had $\mathrm{FC}>(+/-) 4.0$ $(\mathrm{q}<0.05)$.

Table 3B lists genes $(\mathrm{FC}>=(+/-) 1.5$ in diabetic animals that showed changes in expression by P78 treatment (early and late) of which the top 5 include Nhej1 (-37.94), Tceanc2 (+5.76), Ept1 (-4.45), Ugt1a2 (+3.03), and Tmsb15l $(-3.0)$ with FC $>(+/-) 3.0(\mathrm{q}<0.05)$.

\section{P78 Treatment normalized gene expression altered by diabetes}

From this analysis (Table $3 \mathrm{~A}$ and $3 \mathrm{~B}$ ), we identified a small set of genes where the changes in diabetes were substantially $(\sim 50 \%)$ or completely reversed by P78 treatment. These are listed in Table $3 \mathrm{C}$ and rank-ordered by $\mathrm{FC}>=(+/-) 1.5 \quad(\mathrm{q}<0.05)$. Of these, non-homologous end-joining factor 1 (Nhej1) had the highest absolute fold change in expression with both diabetes and treatment. Diabetes induced expression levels of Nhej1 by +32.04 while P78 complete reversed expression by -37.94 fold 


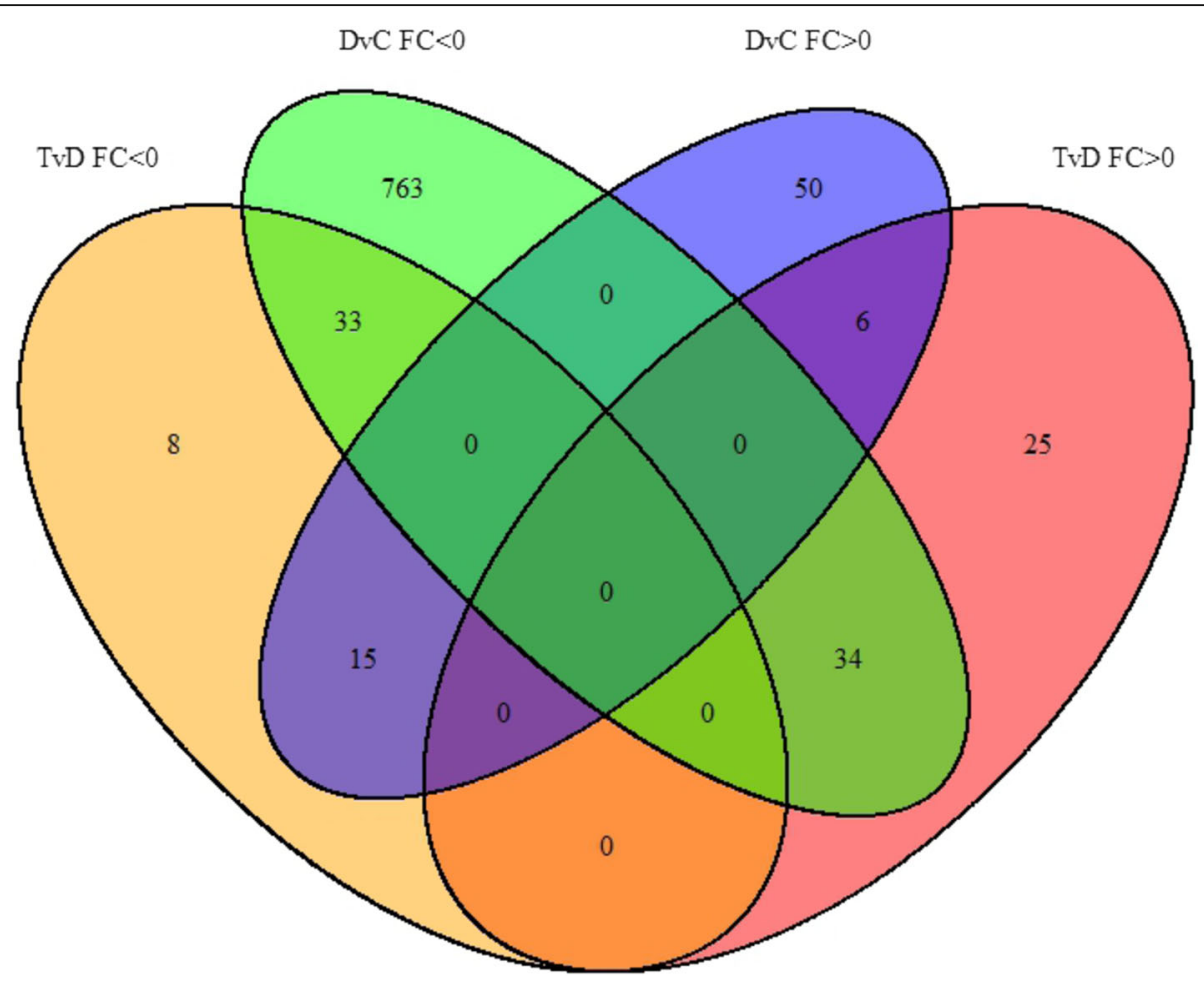

Fig. 4 The Venn diagram shows RNAseq data for only protein-coding genes that are regulated by diabetes or P78 treatment. Expression changes were detected in 934 protein-coding genes with 88 regulated by both diabetes and treatment. 901 coding genes were regulated by diabetes, 121 by P78 treatment (early and late) and 49 coding genes with changes induced by diabetes were reversed by treatment toward control levels of expression $(q<0.05)$

changes. Treatment also completely reversed diabetesinduced expression changes of Mamdc4, Kdm4b, Tmem252, Selm, and Hpd while others were returned in the direction of normal levels from their diabetes-induced state by $\sim 50 \%$ (Table 3C).

Regulation of genes with FC $>=(+/-) 2.0(\mathrm{q}<0.05)$ by diabetes, or treatment (P78 early (ET), and P78 late (LT)) (Table 3C) was subsequently cross-validated for trend in expression by RT-PCR and QRT-PCR (Fig. 5)

Table 2 Number of protein-coding (mRNA) genes that were significantly regulated in the kidney by diabetes and by P78 treatment compared to non-diabetic controls, and those with expression changes in diabetes that were reversed towards normal levels by P78 treatment in the Ins $2^{\text {Akita }}$ mice with FC > $(+/-) 1(q<0.05)$

\begin{tabular}{ll}
\hline Group & \# of Genes \\
\hline Upregulated in D & 71 \\
Downregulated in D & 830 \\
Upregulated with T & 65 \\
Downregulated with T & 56 \\
Upregulated in D, reversed by T & 15 \\
Downregulated in D, reversed by T & 34 \\
\hline
\end{tabular}

with the exception of Mamdc4, whose expression level was below the detection threshold using these PCR conditions. While regulation trends remain the same, some differences in levels of gene regulation between the RNAseq and PCR data were noted, which were possible due to primer specificity, alternatively spliced forms of the genes, RNA integrity, and/or PCR conditions.

This small subset of genes regulated in opposite directions by both diabetes and P78, a treatment previously shown to reduce DN pathology $[24,25]$ may be critically involved in diabetes-induced mechanisms that control the development of the disease.

\section{Transcripts regulated by early and late stage P78 treatment}

Since treatments were given at early and late stage diabetes, we sorted the data to identify genes that were regulated by early treatment and those regulated by late treatment (Table 4). Several transcripts were unique targets of P78 in early and in late stages of diabetes but many were common targets of P78 regardless of the stage of diabetes (Table 4A and 4B) in which case treatment completely reversed diabetes-induced regulation. Nhej1, for example showed regulation from $\mathrm{FC}=+32.0$ in the 
Table 3 Differentially expressed protein coding genes (mRNA) showing the highest fold changes (in either direction) in kidney samples of the Ins $2^{\text {Akita }}$ mice in the diabetic (D) and P78 treatment $(T)$ groups

\begin{tabular}{|c|c|c|c|}
\hline \multicolumn{2}{|l|}{ Increased } & \multicolumn{2}{|l|}{ Decreased } \\
\hline Gene & Fold change & Gene & Fold change \\
\hline \multicolumn{4}{|l|}{ A } \\
\hline Nhej1 & 32.04 & Srd5a2 & -6.55 \\
\hline Ept1 & 8.6 & Aif1 & -6.05 \\
\hline Cyp4a14 & 4.44 & Angptl7 & -4.71 \\
\hline A@7ip & 4.21 & Thrsp & -4.57 \\
\hline Foxn3 & 2.92 & Ucp1 & -4.35 \\
\hline Txnrd1 & 2.76 & Lypd2 & -4.2 \\
\hline Gldc & 2.44 & Ugt1a2 & -4.13 \\
\hline Cyp4a12b & 2.4 & Ly6e & -3.77 \\
\hline Sulf2 & 2.37 & Scd1 1 & -3.7 \\
\hline $\mathrm{Kdm} 4 \mathrm{~b}$ & 2.28 & Inmt & -3.42 \\
\hline Suco & 2.28 & Ang & -3.24 \\
\hline Cyp4a10 & 2.27 & Cyp2d12 & -2.94 \\
\hline Aldh1a7 & 2.21 & Anxa13 & -2.92 \\
\hline Slc18b1 & 2.04 & Car9 & -2.89 \\
\hline Reep6 & 1.97 & Mamdc4 & -2.85 \\
\hline Gsta2 & 1.95 & Cox8b & -2.77 \\
\hline Zbtb18 & 1.94 & Tmem86a & -2.64 \\
\hline Slc38a3 & 1.93 & $\| 34$ & -2.57 \\
\hline Akr1d1 & 1.91 & Ramp3 & -2.51 \\
\hline Etf1 & 1.86 & Acsm3 & -2.5 \\
\hline ApoB & 1.85 & Gusb & -2.48 \\
\hline Erlin1 & 1.8 & Hsd17b11 & -2.43 \\
\hline Pklr & 1.78 & Cyp4b1 & -2.35 \\
\hline Folh1 & 1.77 & Rarres2 & -2.32 \\
\hline $\mathrm{Cfd}$ & 1.71 & Lipo1 & -2.32 \\
\hline Huwe1 & 1.7 & Nudt19 & -2.28 \\
\hline Itgb6 & 1.69 & Cck & -2.28 \\
\hline Cyp4a31 & 1.65 & $\mathrm{H} 2-\mathrm{Ab} 1$ & -2.27 \\
\hline Mtus1 & 1.65 & Tmem37 & -2.22 \\
\hline Selm & 1.64 & Eri2 & -2.2 \\
\hline Cong1 & 1.64 & C1qtnf3 & -2.18 \\
\hline $\mathrm{C} 3$ & 1.61 & Rhod & -2.18 \\
\hline Enpep & 1.6 & Stab1 & -2.14 \\
\hline Mgst1 & 1.56 & Hsd11b1 & -2.13 \\
\hline \multicolumn{4}{|l|}{ B } \\
\hline Tceanc2 & 5.76 & Nhej1 & -37.94 \\
\hline Ugt1a2 & 3.03 & Ept1 & -4.45 \\
\hline Mamdc4 & 2.81 & Tmsb15l & -3 \\
\hline Plk3 & 2.68 & $\mathrm{Kdm} 4 \mathrm{~b}$ & -2.8 \\
\hline
\end{tabular}

Table 3 Differentially expressed protein coding genes (mRNA) showing the highest fold changes (in either direction) in kidney samples of the Ins $2^{\text {Akita }}$ mice in the diabetic (D) and P78 treatment ( $\mathrm{T}$ ) groups (Continued)

\begin{tabular}{|c|c|c|c|}
\hline Lars2 & 2.57 & Selm & -2.47 \\
\hline Sgk1 & 1.76 & Cyp4a14 & -2.22 \\
\hline Tmem252 & 1.75 & Cyp24a1 & -2.02 \\
\hline Adck5 & 1.72 & Alox5ap & -1.92 \\
\hline Psmd13 & 1.68 & Etf1 & -1.71 \\
\hline Chic2 & 1.67 & Hba-a1 & -1.54 \\
\hline Slc25a25 & 1.61 & Odc1 & -1.52 \\
\hline Vps39 & 1.61 & Hbb-bs & -1.51 \\
\hline $\mathrm{Hacl} 1$ & 1.6 & & \\
\hline Gen1l1 & 1.57 & & \\
\hline $\mathrm{Hpd}$ & 1.57 & & \\
\hline Acnat2 & 1.54 & & \\
\hline Fkbp5 & 1.5 & & \\
\hline \multicolumn{4}{|l|}{ C } \\
\hline Gene & DvC & TVD & \\
\hline Nhej1 & 32.04 & -37.94 & \\
\hline Ept1 & 8.6 & -4.45 & \\
\hline Cyp4a14 & 4.44 & -2.22 & \\
\hline Ugt1a2 & -4.13 & 3.03 & \\
\hline Mamdc4 & -2.85 & 2.81 & \\
\hline $\mathrm{Kdm} 4 \mathrm{~b}$ & 2.29 & -2.8 & \\
\hline Etf1 & 1.86 & -1.71 & \\
\hline Chic2 & -1.85 & 1.67 & \\
\hline Tmem252 & -1.67 & 1.75 & \\
\hline Selm & 1.64 & -2.47 & \\
\hline Fkbp5 & -1.6 & 1.5 & \\
\hline $\mathrm{Hpd}$ & -1.58 & 1.57 & \\
\hline
\end{tabular}

A. All protein-coding genes with increased or decreased expression levels by $\mathrm{FC}>(+/-) 1.5(\mathrm{q}<0.05)$ in diabetic relative to wt control B. All coding genes upregulated or downregulated by P78 treatment with $\mathrm{FC}>=(+/-) 1.5(\mathrm{q}<0.05)$ relative to diabetic controls. C. All coding genes with FC $>(+/-) 1.5(q<0.05)$ that were reverted in their expression towards normal levels by P78 treatment (TvD, early and late treatment). Genes are rank ordered by FC (positive or negative values)

diabetic kidney (Table 3A) to -38.55 and -37.33 , for early and late treatments, respectively (Table $4 \mathrm{~A}, 4 \mathrm{~B}$ ). Nhej1, a DNA repair gene, showed the highest fold changes of the protein coding genes regulated by P78 treatments (ET, LT) in both stages of diabetes. We identified sixteen protein-coding genes that were targets of P78 that were significant and reliably altered in expression levels regardless of the diabetic stage when treatment was given (Table $4 \mathrm{~B}$ ). These represented $\sim 50 \%$ similarity in gene expression changes by treatment at both early and late stages of diabetes. With the exception of C3, which showed 


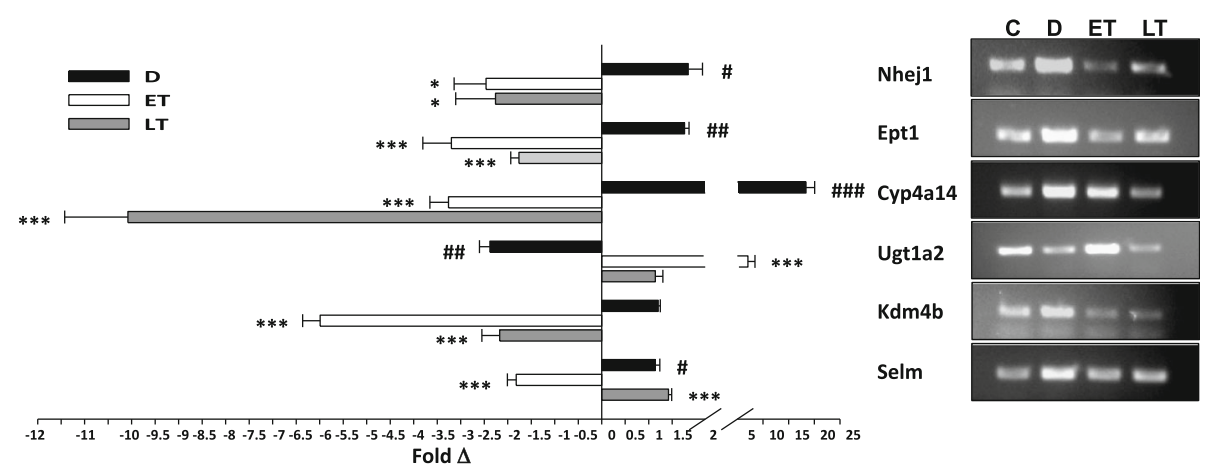

Fig. 5 PCR of pooled kidney samples $(n=7-13)$ from Control (C; wt), Diabetes (D), P78 treatment early stage diabetes (ET) and P78 treatment late stage diabetes (LT). QRT-PCR (left) and RT-PCR (right) analyses confirm the trend of the rRNAseq data for regulation of a group of genes that were modulated with $\mathrm{FC}>=(+/-) 2$ by both diabetes and P78 treatment. Wt controls (C, not indicated as bars in the graph) are set to 1. (DvC: $\# p \leq 0.05$; $\# \# p \leq 0.01 ; \# \# \# \leq 0.001 ; E T V D$ or LTVD: $\left.{ }^{*} p \leq 0.05 ;{ }^{* *} p \leq 0.01 ;{ }^{* * *} p \leq 0.001\right)$

increased expression (+2.06) with early treatment and change in expression in the opposite direction $(-1.41)$ with late treatment, the other 15 genes were regulated in the same direction by P78 and with similar FC in both diabetic stages treated (Table 4B). Many differences in genes showing expression changes were also observed between the early and late stage diabetes treatments. For example in early diabetes treatment increased levels of Ugt1a2 $(+5.41$ FC), S100a9 (+4.23 FC), Plk3 (+3.82 FC), and Lcn2 (+3.38 FC) and decreased levels of Cyp24a1 (-2.51 FC) and Tfpi2 $(-1.76$ FC), genes whose expression changes were not evident with late treatment using our cut off criteria. Others that showed changes in gene expression with late stage diabetes treatment including Alox5ap ( -5.18 FC), Etf1 (-2.48 FC), Psmd13 (+1.98 FC), and Adck5 (+1.89 FC) did not show changes with early stage treatment.

\section{Non-coding small RNAs (miRNA)}

Diabetes and P78 also regulated a group of small noncoding RNA precursor biotypes, with yet unknown or speculative function but are generally believed to control expression and biological function of coding genes. Twenty nine of these with the greatest expression changes $(\mathrm{FC}>(+/-) 5.5(\mathrm{q}<0.05)$ were identified in the diseased kidney compared to wild-type controls (Table 5A) and include miRNA, snRNA, snoRNA, and pseudogene biotypes. miRNAs highly regulated in $\mathrm{DN}$ with $\mathrm{FC}>=(+/-) 20$ $(\mathrm{q}<0.05)$ include Mir1247 (-86.22), Mir142b (-42.04), Mir1905 (+29.52), Mir196a-1 (+22.61), Mir27a (+20.80) (Table 5A). From this analysis, we also identified a set of small RNAs, categorized as miRNA by Gencode, that was highly regulated by diabetes (DvC) and whose expression levels were completely or partially reversed by P78 treatment (TvD). These are rank ordered by FC (up/down) in Table 5B. Of interest in the development and treatment of $\mathrm{DN}$ are those miRNA regulated by diabetes whose expression levels were complete reversed by P78 treatment including Gm24083, Gm25953, and Gm25535, GM25872, Mir1898, Gm25361, Mir7036, Mir7001, and Mir3098. Others including Mir1247 (-86.22) and Mir142b $(-42.04)$ where expression changes in diabetes were not significantly returned to normal levels by treatment. While the functions of many of these sequences are still being elucidated, they represent a class of RNAs that may be useful in understanding the DN pathobiology and in developing treatments for the disease.

\section{Biological function - pathways Ingenuity Pathway Analysis (IPA)}

IPA analysis shows that protein-coding genes regulated by diabetes and returned to near normal levels by treatment (Table 3C) are associated with key biological functions including lipid metabolism, post translational modification, endocrine and hematological functions, cell death and survival, and protein synthesis, all important processes associated with the disease (Fig. 6a). Many of these are also associated with other pathologies including organismal injury and abnormalities, cancer, developmental and hereditary disorders (Fig. 6b)

IPA gene ontology algorithms and KnowledgeBase mining identified several important canonical pathways enriched for the differentially expressed genes (DEG) in our dataset. DEG fell into one of several functionally relevant canonical pathways associated with diabetes and kidney pathology. Figure 7 shows the top pathways represented with $\mathrm{FC}>=(+/-) 1.5$ $(q>0.05)$ and Fig. 8, the percentage of genes regulated relative to those present in the IPA knowledgebase that are assigned to a given pathway and the direction of their regulation (red: upregulated; Green: downregulated) for diabetic (DvC) and P78 treatment (TvD) groups (relative to wt controls). The total number of genes assigned to a pathway in the IPA KnowledgeBase is given to the right of each bar. 
Table 4 Protein coding genes differentially expressed with the highest positive or negative FC in kidney samples of the Ins $2^{\text {Akita }}$ diabetic mice

\begin{tabular}{|c|c|c|c|}
\hline \multicolumn{4}{|l|}{ A } \\
\hline \multicolumn{2}{|l|}{ ET vs D } & \multicolumn{2}{|l|}{ LT vs D } \\
\hline Gene & Fold change & Gene & Fold change \\
\hline Nhej1 & -38.55 & Nhej1 & -37.33 \\
\hline Tceanc2 & 6.03 & Ept1 & -7.87 \\
\hline Ugt1a2 & 5.41 & Tceanc2 & 5.48 \\
\hline S100a9 & 4.23 & Alox5ap & -5.18 \\
\hline Lars2 & 3.99 & Cyp4a14 & -4.74 \\
\hline Plk3 & 3.82 & Mamdc4 & 3.78 \\
\hline Len2 & 3.38 & $\mathrm{Kdm} 4 \mathrm{~b}$ & -2.82 \\
\hline Ept1 & -3.12 & Etf1 & -2.48 \\
\hline $\mathrm{Kdm} 4 \mathrm{~b}$ & -2.79 & Selm & -2.37 \\
\hline Selm & -2.58 & Psmd13 & 1.98 \\
\hline Cyp24a1 & -2.51 & Adck5 & 1.89 \\
\hline Cyp27b1 & 2.33 & Ugt1a6a & 1.76 \\
\hline Arhgap27 & 2.22 & Ndufaf1 & 1.71 \\
\hline Sgk1 & 2.22 & Vps39 & 1.64 \\
\hline Fga & 2.13 & Rfxap & 1.62 \\
\hline Tmem252 & 2.09 & Chic2 & 1.61 \\
\hline C3 & 2.06 & Erlin1 & -1.61 \\
\hline Angpt|4 & 2.05 & Hacl1 & 1.59 \\
\hline Slc25a25 & 2.04 & Hpd & 1.56 \\
\hline Ddit4 & 2.03 & Pnrc2 & 1.52 \\
\hline Ddit3 & 1.92 & & \\
\hline Fkbp5 & 1.81 & & \\
\hline Acnat2 & 1.79 & & \\
\hline Aff4 & 1.79 & & \\
\hline Alas1 & 1.78 & & \\
\hline Tfpi2 & -1.76 & & \\
\hline Tsc22d1 & 1.76 & & \\
\hline Chic2 & 1.72 & & \\
\hline \multicolumn{4}{|l|}{ B } \\
\hline \multicolumn{4}{|c|}{ ET, LT overlapping genes } \\
\hline Gene & ETvD & LTVD & \\
\hline Nhej1 & -38.55 & -37.33 & \\
\hline Ept1 & -3.12 & -7.87 & \\
\hline Tceanc2 & 6.03 & 5.48 & \\
\hline Cyp4a14 & -1.46 & -4.74 & \\
\hline $\mathrm{Kdm} 4 \mathrm{~b}$ & -2.79 & -2.82 & \\
\hline Selm & -2.58 & -2.37 & \\
\hline Etf1 & -1.31 & -2.48 & \\
\hline C3 & 2.06 & -1.41 & \\
\hline
\end{tabular}

Table 4 Protein coding genes differentially expressed with the highest positive or negative FC in kidney samples of the Ins $2^{\text {Akita }}$ diabetic mice (Continued)

\begin{tabular}{lll}
\hline Psmd13 & 1.39 & 1.98 \\
Chic2 & 1.72 & 1.61 \\
Hba-a1 & -1.65 & -1.44 \\
Vps39 & 1.57 & 1.64 \\
Hacl1 & 1.62 & 1.59 \\
Hbb-bs & -1.59 & -1.43 \\
Odc1 & -1.58 & -1.46 \\
Hpd & 1.57 & 1.56 \\
\hline
\end{tabular}

The tables show only those genes that were significant and reliably expressed with FC > =(+/-)1.72 (ET), FC > =(+/-)1.52 (LT) $(\mathrm{q}<0.05)$ and those that were regulated by both treatments (overlapping).These were rank-ordered by highest numerical +/- FC values. A. P78 treatment administered at early (ET, early treatment) or late (LT, late treatment) stage diabetes relative to diabetic controls. 28 genes were regulated by treatment with P78 at the early stage of diabetes and 20 by treatment at the late stage of diabetes. B. The table shows all protein-coding genes that were regulated by P78 in the same direction (except C3) at both stages of diabetes which represented $\sim 50 \%$ of the genes

The open area of each bar represents genes in the pathway that are not represented in our dataset. Pathways were rankordered by IPA base on the significance of the directional change $(-\log (p$-value $)$ and are limited to those enriched in IPA KnowlegeBase.

The graph in Fig. 8a shows a striking trend in diabetesinduced DEGs with mitochondrial dysfunction in the diabetic group relative to wild type controls. The largest functional cluster of genes modulated by diabetes was represented in the mitochodrial dysfunction canonical pathway. Approximately 50\% of the 123 genes assigned to this pathway were differentially expressed by diabetes and $\sim 48 \%$ of these were downregulated. The overall trend observed from this analysis was that diabetes decreased expression of more kidney genes clustered in these pathways $(12 / 16)$ when compared to controls. In three of these pathways associated with chronic renal injury, renal failure, and renal inorganic phosphate homeostasis, all genes were downregulated by diabetes that were present in our kidney dataset.

P78 targeted some of the same pathways as diabetes but fewer genes showed altered expression levels after treatment relative to controls (Fig. 8b). For example, $~ 50 \%$ of the genes in the mitochondrial pathway showed changes in expression in the diabetes group relative to controls while only $\sim 5 \%$ showed altered expression in the treated diabetes group relative to controls. Genes in the P78 treated diabetic mice represented in the cytochrome $P$ 450 and reversible glomerulonephritis associated pathways were all downregulated compared to those in the same pathway for non-treated mice. While those assigned to the recovery from ischemic acute renal failure pathway showed increased levels of expression after treatment 
compared to the non-treated diabetic mice. Since we previously showed that P78 significantly reduced physiological and pathological changes in diabetic nephropathy $[24,25]$ these target pathways and their associated genes may give mechanistic clues to the disease.

\section{Discussion}

In this study we identified a set of transcriptome changes in the kidney of the Ins $2^{\text {Akita }}$ mouse model of diabetic nephropathy (DN) with and without PEDF-P78 peptide treatment. Kidney samples were obtained from our recently published studies in which we showed that continuous infusion of P78 reduced albuminuria, blood urea nitrogen, and progression of DN $[24,25]$. The results from this study provides a panel of biomarkers that shed light into the DN pathology and validate the use of P78 as a therapeutic approach for renal injury.

Using an RNAseq approach [35], we identified a panel of genes dysregulated in DN. Genes showing the greatest decrease in expression in DN include Srd5a2 (5 alpha reductase), Aif1 (Allograft inflammatory factor 1), a protein that modulate insulin secretion in prediabetic rats [36], Angptl7 (angiopoietin-related protein 7), Thrsp (thyroid hormone-inducible hepatic protein), and Ucp1 (thermogenin), found in the mitochondrial membrane of brown adipose tissue [37]. In addition, functional annotation using Ingenuity Pathway analysis and KnowledgeBase revealed the highest enrichment of DN regulated genes in oxidation-reduction reaction and lipid biosynthesis pathways including the genes Srd5a2, Scd1 (Stearoyl-CoA desaturase), HSD17B11 (Estradiol 17-beta-dehydrogenase 11), FASN (Fatty acid synthase), DEGS2 (Delta(4)-desaturase, sphingolipid 2), ALOX15 (Arachidonate 15-lipoxygenase), and PECR (Peroxisomal trans-2-enoyl-CoA reductase) (supplemental data). Scd1, for example, catalyzes the rate-limiting reaction of monounsaturated fatty acid synthesis [38] and is regulated by leptin, a key regulator of obesity-linked diabetes, through insulin independent mechanisms [39] while FASN deregulation is linked to metabolic diseases and insulin-resistance [40]. While clear associations between these genes and $\mathrm{DN}$ are not yet elucidated, their involvement in important biochemical pathways of insulin metabolism, oxidative stress, and obesity, suggest they have important influences on renal injury.

We also identified genes whose expression in diabetic animals was affected by P78 treatment. 12.2\% (138/1129) of all RNA transcripts showing abnormal expression in DN were reverted back to partial or complete normal levels by treatment. Because P78 is effective in reducing many of the pathological features of DN $[24,25]$, we propose that this core set of P78 targets may be responsible for the pathology seen in DN and represent key druggable targets.

Non-homologous end-joining factor 1 (Nhej1), for example, had the highest expression increase in DN $(>30$
Table 5 Differentially expressed precursor miRNAs including Gms assigned as miRNA by Gencode with highest FC in kidney samples of the $\operatorname{lns}^{2^{\text {Akita }}}$ mice

\begin{tabular}{|c|c|c|c|c|}
\hline \multicolumn{2}{|l|}{ A } & \multicolumn{3}{|l|}{ B } \\
\hline Gene & Fold change & Gene & DvC & TVD \\
\hline Mir1247 & -86.22 & Gm24083 & 43.15 & -45.45 \\
\hline Gm24083 & 43.15 & Gm25953 & 34.53 & -36.37 \\
\hline Mir142b & -42.04 & Mir1905 & 29.52 & -5.19 \\
\hline Gm25953 & 34.53 & Gm25535 & -28.56 & 23.41 \\
\hline Mir1905 & 29.52 & Gm27903 & -26.25 & 11.75 \\
\hline Gm25535 & -28.56 & Mir196a-1 & 22.61 & -2.35 \\
\hline Gm27903 & -26.25 & Gm25738 & -17.06 & 10.57 \\
\hline Gm23251 & 22.85 & Gm25872 & -16.27 & 23.35 \\
\hline Mir196a-1 & 22.61 & Gm28010 & 15.43 & -3.08 \\
\hline Mir27a & 20.80 & Mir6991 & 14.82 & -2.65 \\
\hline Mirlet7b & 18.64 & Mir6364 & -12.80 & 8.06 \\
\hline Gm25738 & -17.06 & Gm27684 & 12.51 & -1.86 \\
\hline Mir6386 & 16.74 & Mir328 & -11.78 & 8.56 \\
\hline Gm25872 & -16.27 & Mir1898 & -9.23 & 9.49 \\
\hline Gm28010 & 15.43 & Gm25361 & -8.57 & 10.18 \\
\hline Mir6991 & 14.82 & Gm23134 & -6.45 & 1.80 \\
\hline Mir6981 & 13.64 & Mir7036 & -5.33 & 16.87 \\
\hline Mir6364 & -12.80 & Mir7001 & -4.92 & 4.78 \\
\hline Gm27684 & 12.51 & Mir3098 & 4.61 & -3.51 \\
\hline Gm24515 & 11.93 & Gm27768 & -3.70 & 4.45 \\
\hline Mir328 & -11.78 & Gm25233 & -3.70 & 4.45 \\
\hline Gm25297 & 11.09 & Gm22734 & -3.70 & 4.45 \\
\hline Mir1898 & -9.23 & Gm26043 & 2.96 & -8.34 \\
\hline Gm25361 & -8.57 & Gm22721 & -2.76 & 2.17 \\
\hline Gm27920 & 7.86 & Gm25640 & -2.43 & 6.59 \\
\hline Gm27512 & 7.53 & Mir6363 & -2.08 & 2.27 \\
\hline Gm28033 & 7.13 & Gm25190 & -1.93 & 2.33 \\
\hline Gm23134 & -6.45 & Mir27b & -1.84 & 2.01 \\
\hline Gm23268 & -5.97 & Mir3082 & -1.66 & 1.57 \\
\hline
\end{tabular}

A. miRNAs regulated by diabetes with $\mathrm{FC}>=(+/-) 5.97(\mathrm{q}<0.05)$ relative to control.Genes are listed by highest numerical FC values (positive or negative), B. miRNAs with expression levels altered by diabetes that were reversed by P78 treatment. Genes are listed by highest numerical FC values ( $F C>=+/-1.66$, $q<0.05$ ) in DvC (first column) and the relative regulation values of these same genes after treatment (TVD) given in the second column

fold compared with control) and the highest decrease (>30 fold compared with diabetic) by both early and late P78 treatments. Nhej1 encodes an essential repair factor in double-stranded DNA breaks [41]. Its elevated expression may be a response to diabetes-induced DNA damage in renal proximal tubule cells [42]. The protective role of P78 in reducing assault on the kidney by diabetes-induced DNA damage, may in turn, result in decreased levels of 


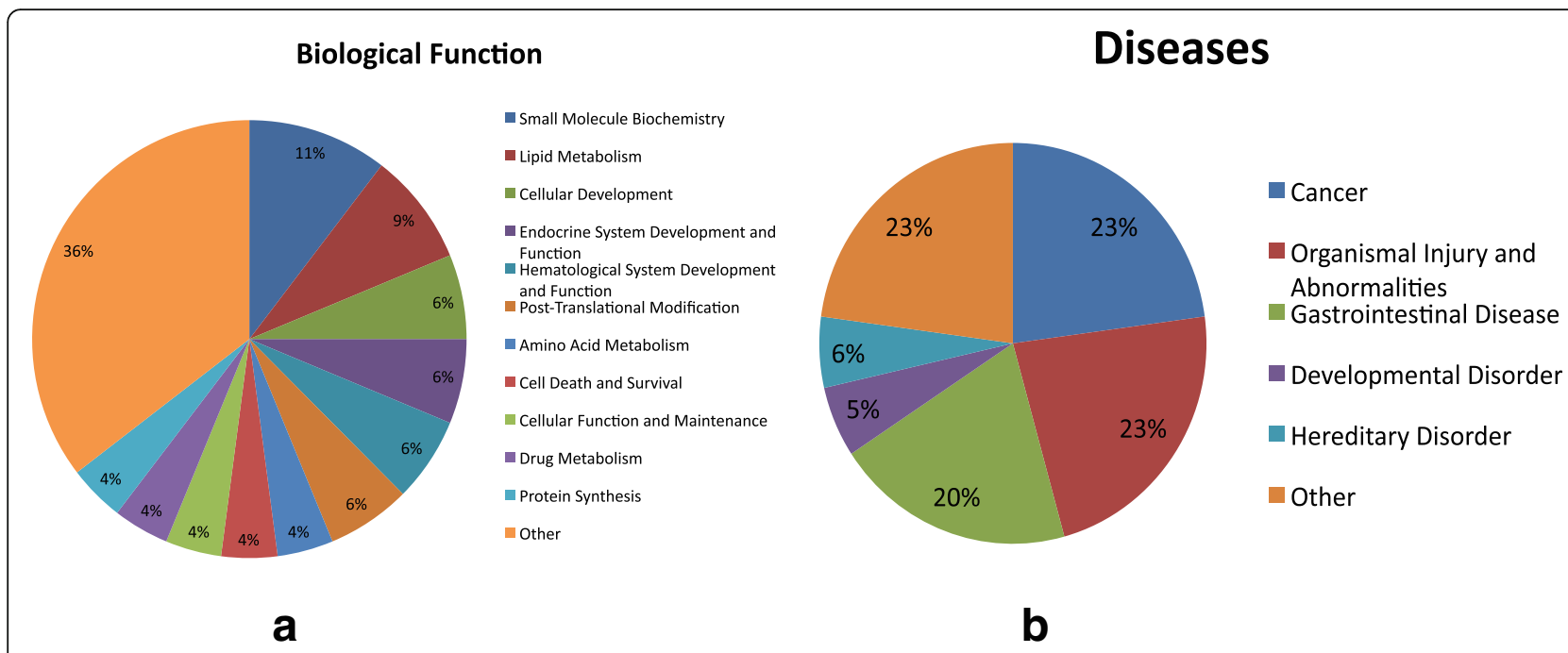

Fig. 6 a. Biological functions associated with 12 target genes (Table 3C) regulated by diabetes that were completely reversed in their expression to control levels by P78 treatment, $\mathbf{b}$. Disease relatedness of these genes are shown with percentage indicating number of genes in each group

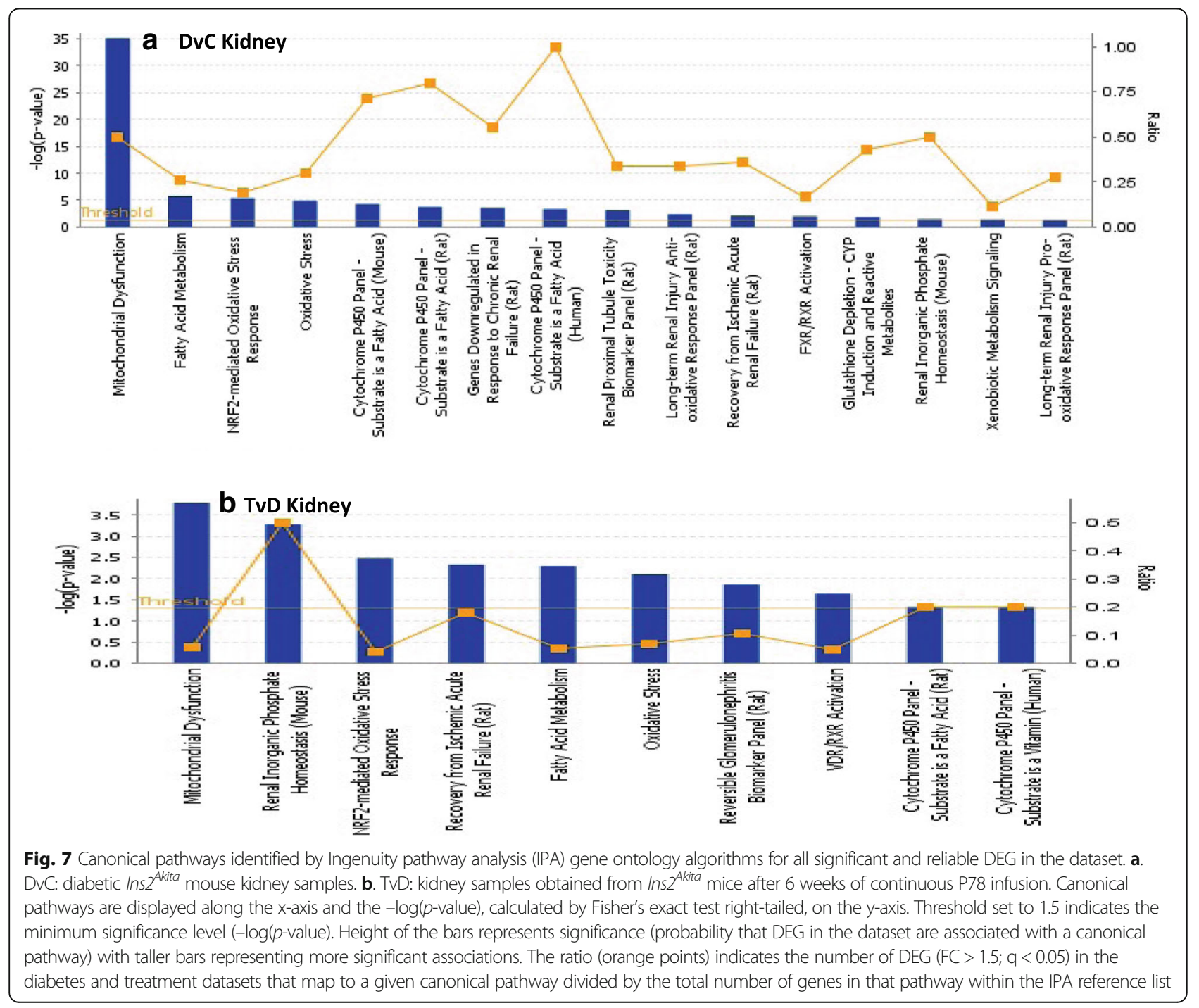




\section{a Diabetic relative to Control: Mammalian kidney}

Mitochondrial Dysfunction

Fatty Acid Metabolism

Nrf2-mediated Oxidative Stress Response

Oxidative Stress

Cytochrome P-450 Panel-Substrate is a Fatty Acid (Mouse)

Cytochrome P-450 Panel - Substrate is a Fatty Acid (Rat)

Genes Downregulated in Response to Chronic Renal Failure (Rat)

Cytochrome P-450 Panel - Substrate is a Fatty Acid (Human)

Renal Proximal Tubule Toxicity Biomarker Panel (Rat)

Long-term Renal Injury Anti-oxidative Response Panel (Rat)

Recovery from Ischemic Acute Renal Failure (Rat)

FXR/RXR Activation

Glutathione Depletion - CYP Induction and Reactive Metabolites

Renal Inorganic Phosphate Homeostasis (Mouse)

Xenobiotic Metabolism Signaling

Long-term Renal Injury Pro-oxidative Response Panel (Rat)

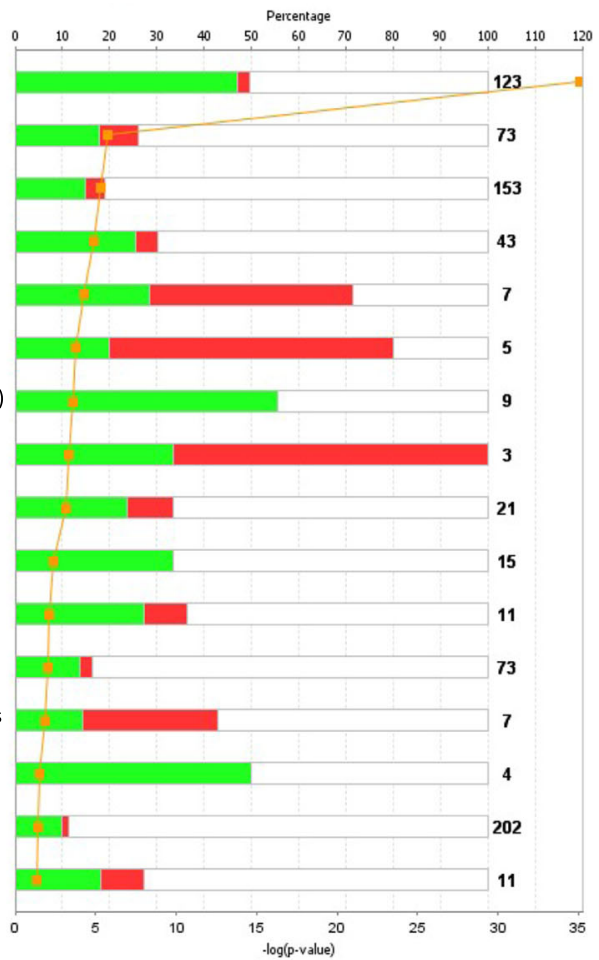

b P78-Treated Diabetic relative to Control: Mammalian kidney

Mitochondrial Dysfunction

Renal Inorganic Phosphate Homeostasis (Mouse)

Nrf2-mediated Oxidative Stress Response

Recovery from Ischemic Acute Renal Failure (Rat)

Fatty Acid Metabolism

Oxidative Stress

Reversible Glomerulonephritis Biomarker Panel (Rat)

VDR/RXR Activation

Cytochrome P-450 Panel - Substrate is a Fatty Acid (Rat)

Cytochrome P-450 Panel-Substrate is a Vitamin (Human)

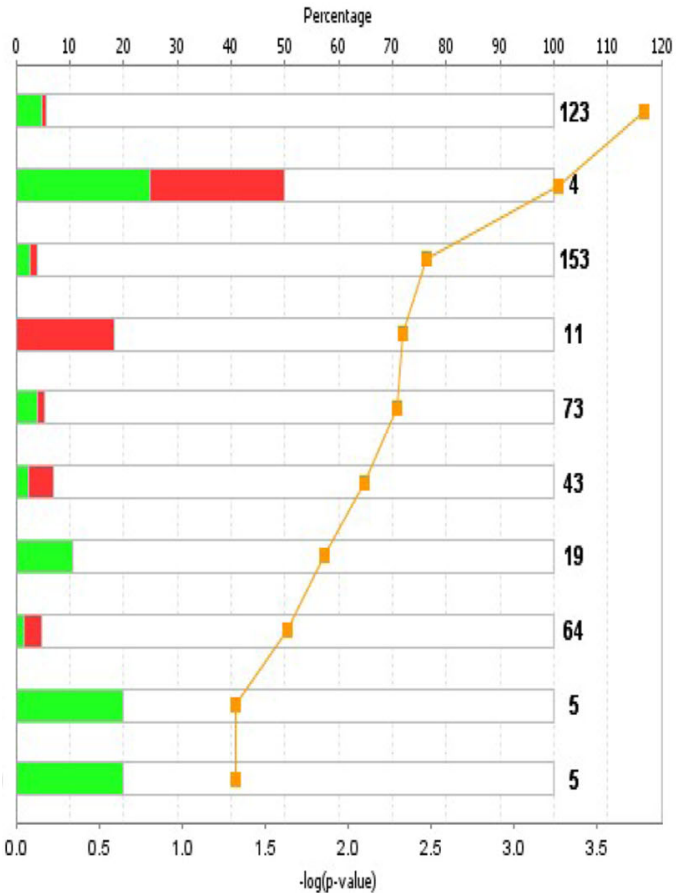

Fig. 8 (See legend on next page.) 
(See figure on previous page.)

Fig. 8 Regulation profile of genes in the canonical pathways most significantly associated with DEG in our RNAseq dataset. a. Diabetic Ins2 ${ }^{\text {Akita }}$ kidney samples relative to control. b. P78-treated diabetic Ins $2^{\text {Akita }}$ kidney samples relative to control. The stacked bars show the percentage of genes ( $y$-axis) distributed according to the direction of gene regulation changes in each canonical pathway ( $x$-axis). Genes that were significantly up-regulated in our dataset are shown in red, those that were down-regulated in green, and those found in the IPA reference gene set that had no overlap with our dataset represented as open bars. The numerical value at the right of each canonical pathway bar indicates the total number of genes present in the IPA Knowledge base for that pathway. The orange line represents the significance of the directional change (-log(p-value) calculated by adjusting the right-tailed Fisher's Exact $t$-test $p$-values using the Benjamini-Hochberg method

Nhej1, thus, implicating genotoxicity as a mechanism in renal injury.

Ept1 (Ethanolaminephosphotransferase 1) and Selm (Selenoprotein $\mathrm{M}$ ), genes related to the selenoprotein gene family, were also in the group regulated by both diabetes and P78. Ept1 is involved in the formation and maintenance of vesicular membranes with relevance to golgi function [43], while Selm codes for a selenocysteine containing protein that maintains redox balance and is linked to obesity and amyloid beta aggregation in the brain $[44,45]$. Both genes were upregulated by diabetes with expression reversed by treatment. These along with Txnrd1 (Thioredoxin reductase 1) which plays a role in oxidative stress and hyperglycemic events [46] form a cluster of genes with roles in selenium metabolism and oxidative stress that may be linked to renal damage. Ugt1a and Mamdc4, which were downregulated and Cyp4a14 and $\mathrm{Kdm} 4 \mathrm{~b}$, which were upregulated in diabetes by 2-4 fold also had near complete restoration of expression levels to control by P78. Ugt1a genetic variants predict high risk for Type 2 diabetes mortality [47] while Mamdc4 deletions are associated with a group of inflammatory axial diseases [48]. Cyp4a14 KO mice have increased hypertension and develop diabetic nephropathy when treated with streptozotocin (STZ) compared to wild-type treated with STZ [49] and Kdm4b, a lysine demethylase, plays a role in regulating chromatin structure [50]. Given their regulation by both diabetes and P78 treatment, and their association with important metabolic functions, these genes are candidate biomarkers with clinical relevance in $\mathrm{DN}$.

We also noted that expression changes in some genes were unique to early or late stage diabetes suggesting that some pathological events/pathways in the diabetic kidney transcriptome are stage-specific. On the other hand since $\sim 64 \%$ of the gene changes in the kidney were similar in the two stages of diabetes, it can be argued that most of the pathology in DN are initiated at a very early stages of the disease. Intervention at either stage with P78 is likely to reduce diabetic insult to the kidney, as we have previously shown [25], through its regulation of these genes. Genes regulated by diabetes and not reversed by treatment are likely to be important as well and may be clustered in yet unknown pathways, which could represent metabolic responses to hyperglycemia that may or may not result in deleterious pathological consequences.

IPA analysis showed mitochondrial dysfunction as the most significantly regulated pathway by diabetes. It was enriched with the highest number (61 genes; $7 \%$ ) of kidney genes showing expression changes in diabetes. After treatment those numbers were reduced by $\sim 85$ $90 \%$ relative to controls. This analysis strongly implicates mitochondrial dysfunction as a key event in the development of $\mathrm{DN}$, regardless of whether it is a primary or secondary target of diabetes, and provides unequivocal evidence for the utility of P78 treatment in its management. In addition, since treatment reversed several diabetes-induced changes in both early and late stage pathology, the P78 peptide has broader clinical relevance for the disease. Other canonical pathways enriched by diabetes-regulated genes were fatty acid metabolism, Nrf2mediated oxidative stress, oxidative stress, and those implicated in renal injury, many of which were less populated after treatment.

Non-coding transcripts including miRNA, snRNA, and snoRNA, were some of the most highly regulated molecules in the diabetic kidney. Small RNAs are known to control the transcriptome, kinome and proteome domains and are involved in normal and pathological gene regulation. Many that showed changes in expression with diabetes were also reversed in the direction of these changes after P78 treatment suggesting that members of this group, with functions yet unknown, are important in development and progression of the disease as well as in understanding its future management.

The Ins $2^{\text {Akita }}$ mouse is a good model of Type I diabetes. However, it will be interesting to see how many of the diabetes-induce gene expression changes we have documented are common to Type II diabetes and how many are found in other diabetic complications such as diabetic retinopathy.

\section{Conclusion}

Diabetes altered expression of a group of coding and non-coding genes in the D2.B6-Ins $2^{\text {Akita }} /$ MatbJ model of DN. Treatment of diabetic mice with P78 reversed expression of a specific subset of these genes. These may be key regulators of diabetes-induced kidney dysfunction 
as P78 was previously shown to reduce physiological and pathological features of DN. While the precise roles of these genes in DN pathology remain unclear, they give initial clues to how the disease develops. Our study provides a set of unique biomarkers to be exploited in $\mathrm{DN}$ and other diabetic complications and suggests that the PEDF-P78 peptide holds promise for the management of this disease.

\section{Abbreviations}

ACE: Angiotensin-converting enzyme; DEG: Differentially expressed genes; DN: Diabetic nephropathy; ESRD: End-stage renal disease; FPKM: Fragments per kilobase of exon per million fragments mapped; IPA: Ingenuity pathway analysis; PEDF: Pigment epithelium-derived factor; VEGF: Vascular endothelial growth factor

\section{Acknowledgement}

We wish to thank Novo Nordisk, Juvenile Diabetes Research Foundation (JDRF), and Frontiers in Eye and Vision Research (FEVR) for funding the work carried out in this study.

\section{Availability of data and materials}

The datasets generated during and/or analyzed in the current study are available in the GEP repository: accession\# GSE87899; http///www.ncbi.nlm.nih.gov/ geo/query/acc.cgi?acc=GSE87899.

\section{Authors' contributions}

AR participated in the RNAseq and IPA analyses, generated tables and figures, and drafted the initial manuscript. AS carried out the RNAseq analysis, generated figures, performed the statistical and IPA analyses, and participated in drafting the manuscript. YI carried out the RNA sequencing and participated in data processing, statistical analysis, and drafting the manuscript. AG cross-validated gene expression studies using PCR and participated in generating PCR figures. JTT conceived and designed the study, analyzed and summarized processed data, and participated in drafting, editing, and revising the manuscript. All authors read and approved the final manuscript.

\section{Competing interests}

The authors declare that they have no competing interests.

\section{Author details}

'Department of Neural and Behavioral Sciences, Penn State College of Medicine, Hershey, USA. ${ }^{2}$ Functional Genome Sciences, Penn State College of Medicine, Hershey, USA. ${ }^{3}$ Department of Ophthalmology, Penn State College of Medicine, Hershey, PA 17033, USA.

Received: 14 January 2016 Accepted: 25 October 2016

Published online: 17 November 2016

\section{References}

1. Wild S, Roglic G, Green A, Sicree R, King H. Global prevalence of diabetes: Estimates for the year 2000 and projections for 2030. Diabetes Care. 2004; 27:1047-53.

2. Centers for Disease Control and Prevention. National diabetes fact sheet: national estimates and general information on diabetes and prediabetes in the United States. Atlanta: US Department of Health and Human Services, Centers for Disease Control and Prevention; 2011.

3. Tuttle KR, Bakris GL, Bilous RW, Chiang JL, de Boer $\mathbb{H}$, Goldstein-Fuchs J, Hirsch IB, Kalantar-Zadeh K, Narva AS, Navaneethan SD, Neumiller JJ, Patel UD, Ratner RE, Whaley-Connell AT, Molitch ME. Diabetic kidney disease: A report from an ADA Consensus Conference. Diabetes Care. 2014;37:2864-83.

4. Dronavalli S, Duka I, Bakris GL. The pathogenesis of diabetic nephropathy. Nat Clin Pract Endocrinol Metab. 2008;4(8):444-52.

5. Singh AK, Mo W, Dunea G, Arruda JA. Effect of glycated proteins on the matrix of glomerular epithelial cells. J Am Soc Nephrol. 1998;9(5):802-10.

6. Cooper ME. Pathogenesis, prevention, and treatment of diabetic nephropathy. Lancet. 1998;352(9123):213-9.

7. Tilton RG, Chang K, Pugliese G, Eades DM, Province MA, Sherman WR, Kilo C, Williamson JR. Prevention of hemodynamic and vascular albumin filtration changes in diabetic rats by aldose reductase inhibitors. Diabetes. 1989;38(10):1258-70.

8. Doublier S, Alvidio G, Lupia E, Ruotsalainen V, Verzola D, Deferrari G, Camussi G. Nephrin expression is reduced in human diabetic nephropathy: evidence for a distinct role for glycated albumin and angiotensin II. Diabetes. 2003:52(4):1023-30.

9. de Vriese AS, Tilton RG, Elger M, Stephan CC, Kriz W, Lameire NH. Antibodies against vascular endothelial growth factor improve early renal dysfunction in experimental diabetes. J Am Soc Nephrol. 2001;12(5):993-1000.

10. Imig JD. Eicosanoids and renal vascular function in diseases. Clin Sci. 2006; 111(1):31-4.

11. Nishikawa T, Kukidome D, Sonoda K, Fujisawa K, Matsuhisa T, Motoshima H, Matsumura T, Araki E. Impact of mitochondrial ROS production on diabetic vascular complications. Diabetes Res Clin Pract. 2007;77 Suppl 1:S41-5.

12. Gross JL, de Azevedo MJ, Silveiro SP, Canani LH, Caramori ML, Zelmanovitz T. Diabetic nephropathy: diagnosis, prevention, and treatment. Diabetes Care. 2005;28(1):164-7.

13. Tombran-Tink J, Barnstable CJ. PEDF: a multifaceted neurotrophic factor. Nat Rev Neurosci. 2003;4(8):628-36.

14. Tombran-Tink J, Barnstable CJ. Therapeutic prospects for PEDF: more than a promising angiogenesis inhibitor. Trends Mol Med. 2003;9(6):244-50.

15. Tombran-Tink J. PEDF in angiogenic eye diseases. Curr Mol Med. 2010;10(3): $267-78$.

16. Tombran-Tink J, Mazuruk K, Rodriguez IR, Chung D, Linker T, Englander E, Chader GJ. Organization, evolutionary conservation, expression and unusual Alu density of the human gene for pigment epithelium-derived factor, a unique neurotrophic serpin. Mol Vis. 1996;2:11.

17. Pina AL, Kubitza M, Brawanski A, Tombran-Tink J, Kloth S. Expression of pigment-epithelium-derived factor during kidney development and aging. Cell Tissue Res. 2007;329(2):329-38.

18. Ogata N, Matsuoka M, Matsuyama K, Shima C, Tajika A, Nishiyama T, Wada M, Jo N, Higuchi A, Minamino K, Matsunaga H, Takeda T, Matsumura M. Plasma concentration of pigment epithelium-derived factor in patients with diabetic retinopathy. J Clin Endocrinol Metab. 2007:92(3):1176-9.

19. Ogata N, Tombran-Tink J, Nishikawa M, Nishimura T, Mitsuma Y, Sakamoto T, Matsumura M. Pigment epithelium-derived factor in the vitreous is low in diabetic retinopathy and high in rhegmatogenous retinal detachment. Am J Ophthalmol. 2001;132(3):378-82.

20. Wang JJ, Zhang SX, Lu K, Chen Y, Mott R, Sato S, Ma JX. Decreased expression of pigment epithelium-derived factor is involved in the pathogenesis of diabetic nephropathy. Diabetes. 2005;54(1):243-50.

21. Wang JJ, Zhang SX, Mott R, Knapp RR, Cao W, Lau K, Ma JX. Salutary effect of pigment epithelium-derived factor in diabetic nephropathy: evidence for antifibrogenic activities. Diabetes. 2006;55(6):1678-85.

22. Li H, Tran W, Hu Y, Mark Saltzman W, Barnstable CJ, Tombran-Tink J. A PEDF N-terminal peptide protects the retina from ischemic injury when delivered in PLGA nanospheres. Exp Eye Res. 2006;83(4):824-33.

23. Liu Y, Leo LF, McGregor C, Grivitishvili A, Barnstable CJ, Tombran-Tink J. Pigment epithelium-derived factor (PEDF) peptide eye drops reduce inflammation, cell death and vascular leakage in diabetic retinopathy in Ins2(Akita) mice. Mol Med. 2012;18:1387-401.

24. Awad AS, Gao T, Grritishvili A, You H, Liu Y, Cooper TK, Reeves WB, Tombran-Tink J. Protective role of small pigment epithelium-derived factor (PEDF) peptide in diabetic renal injury. Am J Physiol Renal Physiol. 2013; 305(6):F891-900.

25. Awad AS, You H, Gao T, Gvritishvili A, Cooper TK, Tombran-Tink J. Delayed Treatment with a Small Pigment Epithelium Derived Factor (PEDF) Peptide Prevents the Progression of Diabetic Renal Injury. PLoS One. 2015;10(7):e0133777.

26. Breyer MD, Böttinger E, Brosius FC 3rd, Coffman TM, Harris RC, Heilig CW, Sharma K; AMDCC. Mouse models of diabetic nephropathy. J Am Soc Nephrol. 2005:16(1):27-45

27. Brosius 3rd FC, Alpers CE, Bottinger EP, Breyer MD, Coffman TM, Gurley SB, Harris RC, Kakoki M, Kretzler M, Leiter EH, Levi M, McIndoe RA, Sharma K, Smithies O, Susztak K, Takahashi N, Takahashi T. Mouse models of diabetic nephropathy. Animal Models of Diabetic Complications Consortium. J Am Soc Nephrol. 2009;20(12):2503-12.

28. Grvitishvili AG, Leung KW, Tombran-Tink J. Codon preference optimization increases heterologous PEDF expression. PLoS One. 2010;5(11):e15056.

29. Awad AS, Kinsey GR, Khutsishvili K, Gao T, Bolton WK, Okusa MD. Monocyte/ macrophage chemokine receptor CCR2 mediates diabetic renal injury. Am J Physiol Renal Physiol. 2011;301(6):F1358-66. 
30. Ryoo S, Gupta G, Benjo A, Lim HK, Camara A, Sikka G, Lim HK, Sohi J, Santhanam L, Soucy K, Tuday E, Baraban E, llies M, Gerstenblith G, Nyhan D, Shoukas A, Christianson DW, Alp NJ, Champion HC, Huso D, Berkowitz DE. Endothelial arginase II: a novel target for the treatment of atherosclerosis. Circ Res. 2008;102(8):923-32.

31. Morris Jr SM, Gao T, Cooper TK, Kepka-Lenhart D, Awad AS. Arginase-2 mediates diabetic renal injury. Diabetes. 2011;60(11):3015-22.

32. Trapnell C, Pachter L, Salzberg SL. TopHat: discovering splice junctions with RNA-Seq. Bioinformatics. 2009;25:1105-11.

33. Trapnell C, Williams BA, Pertea G, Mortazavi A, Kwan G, van Baren MJ, Salzberg SL, Wold BJ, Pachter L. Transcript assembly and quantification by RNA-Seq reveals unannotated transcripts and isoform switching during cell differentiation. Nat Biotechnol. 2010;28:511-5.

34. Wang L, Feng Z, Wang X, Wang X, Zang X. DEGseq: an R package for identifying differentially expressed genes from RNA-seq data. Bioinformatics. 2010;26(1):136-8.

35. Mortazavi A, Williams BA, Kenneth McCue K, Lorian Schaeffer L, Wold B. Mapping and quantifying mammalian transcriptomes by RNA-Seq. Nat Methods. 2008;5:621-8.

36. Chen ZW, Ahren B, Östenson CG, Cintra A, Bergman T, Möller C, Fuxe K, Mutt $V$, Jörnvall $H$, Efendic S. Identification, isolation, and characterization of daintain (allograft inflammatory factor 1), a macrophage polypeptide with effects on insulin secretion and abundantly present in the pancreas of prediabetic BB rats. Proc Natl Acad Sci U S A. 1997;94(25):13879-84.

37. Jun-jing J, Yun-bo T, Zhen-hui C, Lin-li T, Xi Z, Si-zhen G, Chang-rong G, Qiu-Ye $\mathrm{L}$, Jois M. The polymorphisms of UCP1 genes associated with fat metabolism, obesity and diabetes. Mol Biol Rep. 2010;37(3):1513-22.

38. Zhang L, Ge L, Parimoo S, Stenn K, Prouty SM. Human stearoyl-CoA desaturase: alternative transcripts generated from a single gene by usage of tandem polyadenylation sites. Biochem J. 1999;340(1):255-64

39. Biddinger SB, Miyazaki M, Boucher J, Ntambi JM, Kahn CR. Leptin suppresses stearoyl-CoA desaturase 1 by mechanisms independent of insulin and sterol regulatory element-binding protein-1c. Diabetes. 2006;55(7):2032-41.

40. Menendez JA, Vazquez-Martin A, Ortega FJ, Fernandez-Real JM. Fatty Acid Synthase: Association with Insulin Resistance, Type 2 Diabetes, and Cancer. Clin Chem. 2009:55(3):425-38.

41. Wu Q, Ochi T, Matak-Vinkovic D, Robinson CV, Chirgadze DY, Blundell TL. Non-homologous end-joining partners in a helical dance: structural studies of XLF-XRCC4 interactions. Biochem Soc Trans. 2011;39(5):1387-92.

42. Freitas HS, Schaan BD, Seraphim PM, Nunes MT, Machado UF. Acute and short-term insulin-induced molecular adaptations of GLUT2 gene expression in the renal cortex of diabetic rats. Mol Cell Endocrinol. 2005;237(1-2):49-57.

43. Henneberry AL, Lagace TA, Ridgway ND, McMaster CR. Phosphatidylcholine synthesis influences the diacylglycerol homeostasis required for SEC14pdependent Golgi function and cell growth. Mol Biol Cell. 2001;12(3):511-20.

44. Pitts MW, Reeves MA, Hashimoto AC, Ogawa A, Kremer P, Seale LA, Berry MJ. Deletion of selenoprotein M leads to obesity without cognitive deficits. J Biol Chem. 2013;288(36):26121-34.

45. Chen P, Wang RR, Ma XJ, Liu Q, Ni JZ. Different Forms of Selenoprotein M Differentially Affect A Aggregation and ROS Generation. Int J Mol Sci. 2013; 14(3):4385-99.

46. Patel H, Chen J, Das KC, Kavdia M. Hyperglycemia induces differential change in oxidative stress at gene expression and functional levels in HUVEC and HMVEC. Cardiovasc Diabetol. 2013;12:142.

47. Cox AJ, Ng MC, Xu J, Langefeld CD, Koch KL, Dawson PA, Carr JJ, Freedman Bl, Hsu FC, Bowden DW. Association of SNPs in the UGT1A gene cluster with total bilirubin and mortality in the Diabetes Heart Study. Atherosclerosis. 2013;229(1):155-60.

48. O'Rielly DD, Uddin M, Codner D, Hayley M, Zhou J, Pena-Castillo L, Mostafa AA, Hasan SM, Liu W, Haroon N, Inman R, Rahman P. Private rare deletions in SEC16A and MAMDC4 may represent novel pathogenic variants in familial axial spondyloarthritis. Ann Rheum Dis. 2015;doi:10.1136/annrheumdis2014-206484.

49. Gangadhariah MH, Luther JM, Garcia V, Paueksakon P, Zhang MZ, Hayward SW, Love HD, Falck JR, Manthati VL, Imig JD, Schwartzman ML, Zent R, Capdevila $\mathrm{JH}$, Pozzi A. Hypertension is a major contributor to 20-hydroxyeicosatetraenoic acid-mediated kidney injury in diabetic nephropathy. J Am Soc Nephrol. 2015; 26(3):597-610.

50. Young LC, McDonald DW, Hendzel MJ. Kdm4b histone demethylase is a DNA damage response protein and confers a survival advantage following p-irradiation. J Biol Chem. 2013;288:21376-88.

\section{Submit your next manuscript to BioMed Central and we will help you at every step:}

- We accept pre-submission inquiries

- Our selector tool helps you to find the most relevant journal

- We provide round the clock customer support

- Convenient online submission

- Thorough peer review

- Inclusion in PubMed and all major indexing services

- Maximum visibility for your research

Submit your manuscript at www.biomedcentral.com/submit
Biomed Central 